\title{
Thyroid structure and size and two-year follow-up of solitary cold thyroid nodules in an unselected population with borderline iodine deficiency
}

\author{
Nils Knudsen ${ }^{1,4}$, Hans Perrild ${ }^{1}$, Erik Christiansen ${ }^{2}$, Susanne Rasmussen ${ }^{3}$, Harriet Dige-Petersen ${ }^{3}$ \\ and Torben Jørgensen ${ }^{4}$ \\ ${ }^{1}$ Department of Internal Medicine I and ${ }^{2}$ Department of Biochemistry, Bispebjerg Hospital, Copenhagen, Denmark, ${ }^{3}$ Department of Clinical Physiology \\ and Nuclear Medicine and ${ }^{4}$ Centre of Preventive Medicine, Glostrup Hospital, University of Copenhagen, Copenhagen, Denmark
}

(Correspondence should be addressed to N Knudsen, Department of Internal Medicine I, Bispebjerg Hospital, DK-2400 Copenhagen NV, Denmark: Email: nils.knudsen@dadlnet.dk)

\begin{abstract}
Objective: Multinodular goitre has been found with a high prevalence in iodine-deficient areas, but less frequently in iodine-replete areas; the iodine intake sufficient to prevent goitre has not been established, however.

Methods: We report data from an ultrasonic investigation of the thyroid glands of 2656 randomly selected subjects aged 41 to 71 years in an area with borderline iodine deficiency.

Results: Median iodine concentration in spot urine samples was $70 \mu \mathrm{g} / \mathrm{l}$. Multinodular thyroid structure was found in $23 \%$ of the population, increasing in women from 20 to $46 \%$ with increasing age, and in men from 7 to $23 \%$. Solitary, scintigraphically cold, thyroid nodules $>10 \mathrm{~mm}$ were found in $2.4 \%$ of the population with the same prevalence in the different age and sex groups. Two years of follow-up of these cold nodules revealed no signs of malignancies. Median thyroid volume was $11.0 \mathrm{ml}$. Thyroid enlargement (>18 ml for women and $>25 \mathrm{ml}$ for men) was found among $13.1 \%$ of the women and $6.2 \%$ of the men, and the prevalence increased with age. The presence of thyroid nodules was related to positive anti-thyroperoxidase antibody (TPO Ab) titres, whereas thyroid enlargement was associated with iodine excretion $<50 \mu \mathrm{g} /$ day.

Conclusions: Thyroid enlargement was associated with low iodine excretion and median thyroid volume was slightly increased compared with iodine-replete areas. Multinodular thyroid structure was found with a high prevalence and was associated with TPO Ab $>200 \mathrm{kU} / \mathrm{l}$. Cold thyroid nodules were moderately prevalent, with no cases of detected malignancies during 2 years of follow-up.
\end{abstract}

European Journal of Endocrinology 142 224-230

\section{Introduction}

Epidemiological investigations with ultrasonic examination of the thyroid gland have generally found variations between the studied populations in thyroid volume as well as the prevalence of structural abnormalities in the thyroid gland. Some of this variation may be due to differences in the studied populations with respect to age and sex and the selection procedure, as few studies comprised an unselected part of the general population. Thyroid volume is increased in areas with mild iodine deficiency compared with iodine-replete areas, especially among the elderly part of the population (1-3).

It has also been found that the prevalence of toxic nodular goitre is markedly increased in iodine-deficient regions (4), especially among the elderly part of the population. Even in areas with borderline iodine deficiency, the prevalence of nodular goitre in particular seems high $(5,6)$. The minimal level of iodine intake sufficient to prevent or minimize the development of nodular goitre has not been established.

Thyroid nodules have been reported to be a relatively common finding in other epidemiological surveys. When palpation is used as a screening procedure, prevalences of thyroid nodules of $4-7 \%$ are found (7-11) and, using ultrasonography nodules, can be detected in up to $50 \%$ of the studied population $(1,12-15)$. In clinical practice, this poses the problem that thyroid cancer, although it will be present in very few of such nodules, has to be ruled out. Current non-invasive methods, including cytology, do not have sufficiently high negative predictive value for malignancy. 
The purpose of this study was to determine thyroid volume and the prevalence of goitre and thyroid structural abnormalities in an unselected population in an area with borderline iodine deficiency and to investigate the natural course of solitary, scintigraphically cold, thyroid nodules.

\section{Subjects and methods}

\section{Subjects}

The investigation was carried out in 1993-94 as a 10-year follow-up of a cohort formed in 1982-84 in the western suburbs of Copenhagen. In all, 4073 people were invited and $2656(65.2 \%)$ participated. They represented men and women born in Denmark in the years 1922, 1932, 1942 or 1952, but were otherwise randomly selected from the Civil Registration System, in which every person living in Denmark is registered. The cohort has previously been described in more detail (16).

\section{Methods}

The participants were invited by letter, and in the case of no reply, a reminder was sent. If there was still no response, an attempt was made to contact the subject by phone, and if that was unsuccessful, a final letter was sent.

Before the examination, the participants filled in questionnaires concerning medication and previously diagnosed thyroid disease. A physical examination of the neck was done, and weight and height were registered. Ultrasonic examination of the thyroid was conducted with a Brüel and Kjær 3535 scanner (Naerum, Denmark) and a $7.5 \mathrm{MHz}$ curved array transducer. Thyroid volume was calculated using the formula for a rotation ellipsoid as length $\times$ width $\times$ depth $\times \pi / 6$ for each lobe of the gland. Thyroid structure was described for each lobe as homogeneous, uninodular, multinodular or cystic. The gland was only classified as multinodular if distinct nodules were visible; micronodularity (that is an irregular echo pattern) was not registered. In the case of a single nodule, the maximum diameter of the nodule was registered; nodules with a diameter of less than $10 \mathrm{~mm}$ were ignored. A ${ }^{99 \mathrm{~m}} \mathrm{Tc}-$ pertechnetate scintigraphy using a pinhole collimator was suggested to all participants with solitary nodules $>10 \mathrm{~mm}(n=236)$, participants with a thyroid volume of $>40 \mathrm{ml}(n=32$, all with a nodular thyroid gland at ultrasound), and participants with palpable nodules in the thyroid even if thyroid volume was $<40 \mathrm{ml}(n=8)$.

On the basis of the ultrasonic examination - and in some cases scintigraphy $(n=160)$ - the participants were classified into seven groups according to thyroid structure: normal (no nodules or cysts); multinodular (more than one nodule); solitary 'cold' nodule (single lesion $>10 \mathrm{~mm}$ without uptake at scintigraphy); solitary functioning nodule (single nodule $>10 \mathrm{~mm}$ at ultrasonography with normal ${ }^{99 \mathrm{~m}} \mathrm{Tc}$ uptake at scintigraphy); solitary 'hot' nodule (single lesion $>10 \mathrm{~mm}$ with increased ${ }^{99 \mathrm{~m}} \mathrm{Tc}$ uptake at scintigraphy); cystic (one or more cysts at ultrasonography and no solid nodules); or non-classified single nodule (participant refused scintigraphy). Participants with solitary cold nodules were told about the possible implications of this and advised to consult their general practitioner, who would then eventually refer the patient to the local endocrinological centre for further examination. Thyroid enlargement at ultrasonographic examination was defined as a volume exceeding $18 \mathrm{ml}$ for women and $25 \mathrm{ml}$ for men, corresponding to mean thyroid volume $+3 \mathrm{SD}$ in iodine-sufficient populations (17).

For the correlation between thyroid structure and thyroid function, hyperthyroidism was defined as serum thyrotrophin (TSH) $<0.15 \mathrm{mU} / \mathrm{l}$ or known hyperthyroidism. Hypothyroidism was defined as serum TSH $>5 \mathrm{mU} / \mathrm{l}$ or known hypothyroidism. Anti-thyroperoxidase antibody (TPO Ab) values were divided into three groups: <100 kU/l (negative), 100-200 kU/l (borderline) and $>200 \mathrm{kU} / \mathrm{l}$ (positive). Biochemical methods have previously been described in detail (18). Iodine excretion was evaluated through casual urine samples analysed for iodine concentration with a SandallKolthoff reaction after digestion with hydrochloric acid, and creatinine $(\mathrm{Cr})$ concentration after the principles of Jaffe. Iodine excretion was expressed as an age- and sex-corrected iodine/Cr ratio to give values comparable to $24 \mathrm{~h}$ excretion and to allow stratification of the cohort (18). All participants who had had a solitary cold nodule diagnosed at the investigation were invited to a follow-up study 2 years after the first investigation. At the follow-up, a new ultrasonographic investigation and a new ${ }^{99 \mathrm{~m}} \mathrm{Tc}$ scintigraphy were performed. The examiners were the same as in the original investigation and the evaluation was done without knowledge of the precise results from the first investigation; they were aware, though, that it was a follow-up study on solitary cold nodules.

The investigation was approved by the Regional Research Ethics Committee of Copenhagen County, and all participants gave written informed consent.

\section{Statistics}

All data processing was done with SPSS version 8.0 statistical software. For comparison of thyroid volumes, Mann-Whitney and Kruskall-Wallis tests were used, as data were not normally distributed, and for dichotomous variables Pearson Chi-square tests were used. For comparison with previous studies, a one-sample $t$-test was used. Logistic regression was used in the analysis of the influence of iodine excretion and TPO Ab levels on thyroid nodules and thyroid enlargement to take age and sex into account; no significant interactions were found. Confidence intervals (CIs) were set to 95\%. 


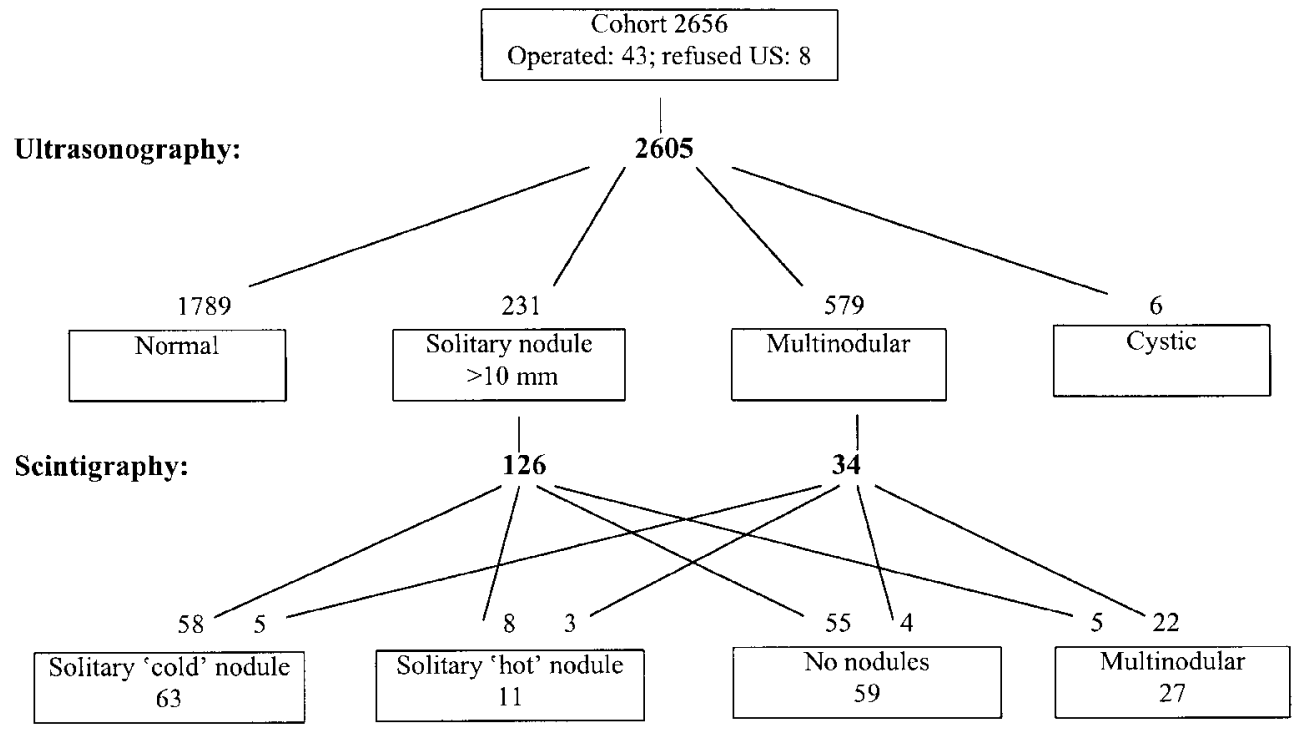

Figure 1 Results of ultrasonography of 2605 unselected participants from an area with borderline iodine deficiency, and scintigraphy in the case of a solitary nodule of more than $10 \mathrm{~mm}$, thyroid volume of more than $40 \mathrm{ml}$, or a palpable nodule. Among the participants with solitary nodules $>10 \mathrm{~mm}$ in diameter, $40 \%$ refused scintigraphy. In the multinodular group, 32 had a thyroid volume $>40 \mathrm{ml}, 8$ had smaller glands but palpable nodules.

\section{Results}

Previous operation for thyroid disease was reported by 43 participants $(1.6 \%)$. Out of these, 24 subjects had been operated for goitre, 11 had been operated due to hyperthyroidism, 7 due to a nodule in the thyroid and 1 due to cancer. These subjects were excluded from further analyses.

Casual urine samples were available from 2382 participants $(89.7 \%)$. Median iodine concentration in the casual samples was $70 \mu \mathrm{g} / \mathrm{l}$ and median iodine $/ \mathrm{g} \mathrm{Cr}$ was $76 \mu \mathrm{g} / \mathrm{g}$. According to Bourdoux (19) the area should be classified as borderline iodine deficient. Median iodine excretion was $103 \mu \mathrm{g} /$ day as estimated from the age- and sex-corrected iodine/Cr ratio (18), and 271 participants $(9.7 \%)$ had an estimated iodine excretion $<50 \mu \mathrm{g} /$ day.

\section{Thyroid nodules}

The results of ultrasonography and ${ }^{99 \mathrm{~m}} \mathrm{Tc}$ scintigraphy are shown in Fig. 1, and the final classification of the participants on the basis of these results stratified according to sex is shown in Table 1; ultrasonography was not performed in eight participants who refused the examination. Among participants with multinodular thyroid structure, 3\% of subjects without thyroid enlargement and 37\% with thyroid enlargement had palpable goitre at a routine clinical examination. For participants with solitary nodules these figures were 3 and $24 \%$ respectively, and for participants without nodules 0.3 and $9.4 \%$. The prevalence of thyroid multinodularity at ultrasonography increased from $19 \%$ in the 41 -year-old women to $45 \%$ in the 71 year-old women and from $7 \%$ in 41 -year-old men to $22 \%$ in 71-year-old men, whereas the prevalence of solitary nodules was essentially the same in all age groups.

The relationship between thyroid dysfunction and thyroid structure is shown in Table 2, which shows that the major part of participants with hyperthyroidism had multinodular glands (comparison with normal thyroid function, $P<0.001$, Pearson Chi-square). In a

Table 1 Final classification (number and per cent) of thyroid structure of 2605 unselected participants from an area with borderline iodine deficiency according to results from ultrasonography and in some cases scintigraphy. Participants are stratified by sex. Subjects with previous thyroid surgery were excluded $(n=43)$.

\begin{tabular}{|c|c|c|c|c|c|c|c|c|}
\hline Sex & Normal & Multinodular & $\begin{array}{c}\text { Cold } \\
\text { nodule }\end{array}$ & $\begin{array}{c}\text { Hot } \\
\text { nodule }\end{array}$ & $\begin{array}{l}\text { Isoactive } \\
\text { nodule }\end{array}$ & $\begin{array}{l}\text { Non-classified } \\
\text { nodule }\end{array}$ & Cystic & Total \\
\hline Female & $781(60.9 \%)$ & 404 (31.5\%) & $30(2.3 \%)$ & $9(0.7 \%)$ & $18(1.4 \%)$ & $39(3.0 \%)$ & $2(0.2 \%)$ & $1283(100.0 \%)$ \\
\hline Male & $1014(76.7 \%)$ & $188(14.2 \%)$ & $33(2.5 \%)$ & $3(0.2 \%)$ & $28(2.1 \%)$ & $52(4.0 \%)$ & $4(0.3 \%)$ & 1322 (100.0\%) \\
\hline Total & $1795(68.9 \%)$ & $592(22.7 \%)$ & $63(2.4 \%)$ & $12(0.5 \%)$ & $46(1.8 \%)$ & $91(3.5 \%)$ & $6(0.2 \%)$ & 2605 (100.0\%) \\
\hline
\end{tabular}


Table 2 Thyroid structure (number and per cent) at ultrasonography in different groups of thyroid function in 2605 unselected participants from an area with borderline iodine deficiency. Thyroid function is based on anamnestic information and present biochemical thyroid status. Subclinical thyroid disease is included in the hyper- and hypothyroid groups. Subjects with previous thyroid surgery were excluded $(n=43)$.

\begin{tabular}{|c|c|c|c|c|c|}
\hline & Normal & Multinodular & Solitary nodule & Cystic & Total \\
\hline Hyperthyroid & 25 (32.5\%) & 45 (58.4\%) & $7(9.1 \%)$ & 0 & 77 (100.0\%) \\
\hline Euthyroid & $1743(70.2 \%)$ & $512(20.6 \%)$ & $222(8.9 \%)$ & $6(0.2 \%)$ & $2483(100.0 \%)$ \\
\hline Hypothyroid & $21(46.7 \%)$ & $22(48.9 \%)$ & $2(4.4 \%)$ & 0 & $45(100.0 \%)$ \\
\hline Total & $1789(68.7 \%)$ & $579(22.2 \%)$ & $231(8.9 \%)$ & $6(0.2 \%)$ & $2605(100.0 \%)$ \\
\hline
\end{tabular}

logistic regression analysis including age and sex, multinodular thyroid structure was related to TPO $\mathrm{Ab}$ values >200 kU/l (odds ratio (OR) 1.45; CI 1.08$1.94)$, but not to borderline values from 100 to $199 \mathrm{kU} / \mathrm{l}$ (OR 1.08; CI 0.67-1.28), whereas no relationship was found between multinodular thyroid structure and iodine excretion $<50 \mu \mathrm{g} /$ day (OR 1.06; CI 0.77-1.48) in the entire cohort.

\section{Thyroid volume}

The median thyroid volume for the entire group was $11.1 \mathrm{ml}$ (mean $13.0 \mathrm{ml}$, range $1.2-108.9 \mathrm{ml}$ ). The volume was larger for men than for women $(P<0.001$, Mann-Whitney), whereas no differences between the age groups were found $(P=0.15$, Kruskall-Wallis, Fig. 2 ). However, the significant difference between men and women disappeared, when a correction for differences in weight was done by expressing thyroid volume in $\mathrm{ml} / \mathrm{kg}$ body weight $(P=0.06$, Mann-Whitney). Thyroid size was more closely related to body weight than to height or the square of the height.
Thyroid enlargement, defined as $>18 \mathrm{ml}$ for women and $>25 \mathrm{ml}$ for men (17), was found in $6.2 \%$ of the men and $13.1 \%$ of the women $(P<0.001$, Mann-Whitney) with increasing prevalences with increasing age $(P=0.004$, Kruskal-Wallis, Fig. 3). If only the normally structured glands were included, no difference in prevalence of thyroid enlargement was found between the age and sex groups $(P=0.97$ for age, Mann-Whitney and 0.54 for sex, KruskalWallis) (Fig. 3), thus the increased prevalence of thyroid enlargement among women and in old age is entirely due to increasing nodularity of the glands.

Thyroid enlargement was found in $8.5 \%$ of participants with normal thyroid function compared with $52 \%$ among subjects with unrecognized hyperthyroidism and $17 \%$ among subjects with unrecognized hypothyroidism. In a logistic regression analysis of the entire cohort, controlling for age and sex, thyroid enlargement was related to iodine excretion $<50 \mu \mathrm{g} /$ day (OR 1.84: CI 1.24-2.74) but not to TPO Ab values $>200 \mathrm{kU} / \mathrm{l}$ (OR 1.24; CI 0.84-1.91).

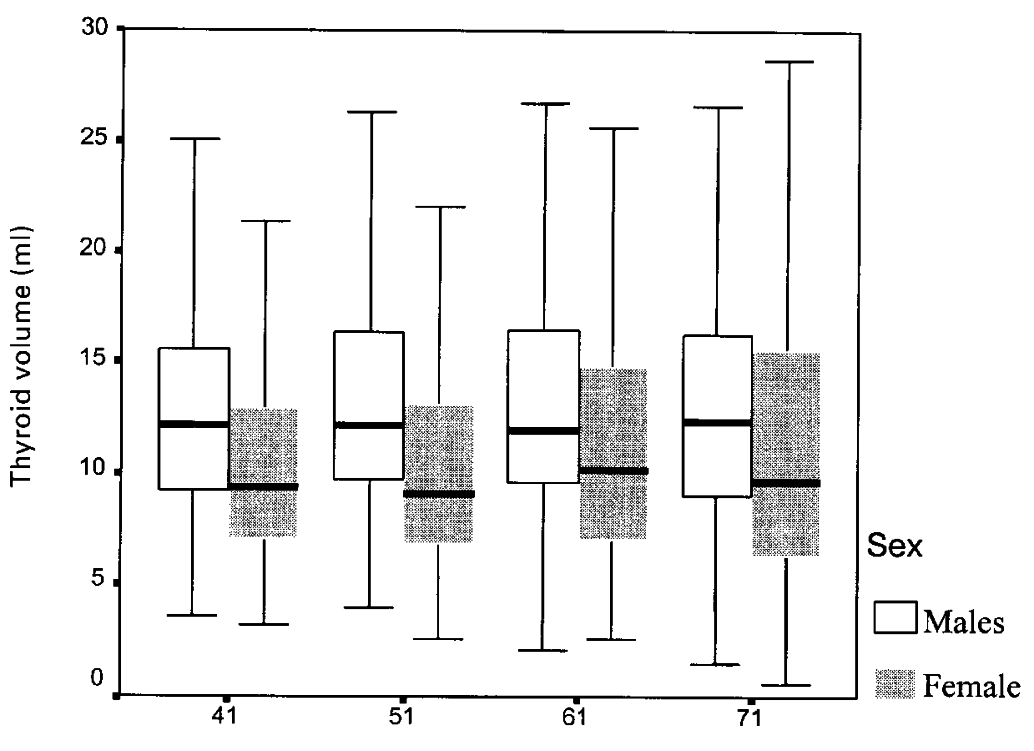

Age, years
Figure 2 Thyroid volume at ultrasonography in 2605 unselected participants from an area with borderline iodine deficiency. Participants are stratified according to age and sex. Subjects with previous thyroid surgery were excluded $(n=43)$. 


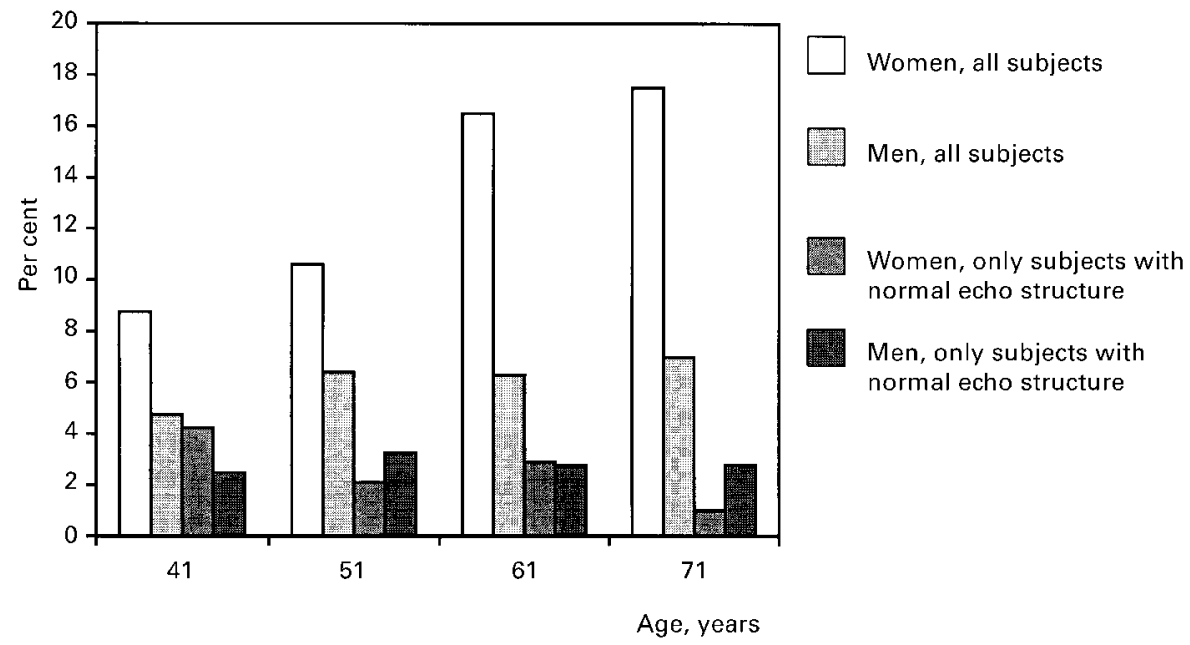

Figure 3 Percentage with thyroid enlargement in an unselected population with borderline iodine deficiency. Thyroid enlargement is defined as a volume exceeding $18 \mathrm{ml}$ for women and $25 \mathrm{ml}$ for men. Columns represent percentage with thyroid enlargement within the two sexes and among either all participants or only the subgroup with normal thyroid structure at ultrasonography.

\section{Nodular functional status}

The solitary nodules $(n=231)$ had a diameter between 10 and $20 \mathrm{~mm}$ in $57 \%$ of the cases. Of all the solitary nodules, $5.9 \%$ were palpable at a routine clinical examination. Among the participants with solitary nodules $96(40.7 \%)$ refused scintigraphy of the thyroid, and most of these had nodules less than $20 \mathrm{~mm}$ in diameter. The probability of a solitary nodule being classified as cold at scintigraphy increased with increasing diameter, as $22 \%$ of nodules less than $20 \mathrm{~mm}, 54 \%$ of nodules $20-30 \mathrm{~mm}$, and $67 \%$ of nodules larger than $30 \mathrm{~mm}$ were classified as cold. No relationship was found between the presence of solitary, cold thyroid nodules and age, sex, low iodine excretion or TPO $\mathrm{Ab}>200 \mathrm{kU} / \mathrm{l}$ in a logistic regression analysis. Of the 12 participants with a solitary nodule with increased ${ }^{99 \mathrm{~m}} \mathrm{Tc}$ uptake at scintigraphy, 5 had marked suppression of the rest of the gland.

\section{Follow-up of cold nodules}

In the follow-up study all 63 participants with a solitary, cold thyroid nodule were invited. Fourteen participants had been operated since the original investigation, 13 because of the information given to them after the investigation without increasing complaints from the goitre, and 1 because of a sensation of growth of the goitre. The histological diagnoses were reviewed in the patients' medical files and no reports of malignancies were found. Of the remaining 49 participants, 45 participated in the follow-up. A change in diameter at the ultrasonic investigation of at least $5 \mathrm{~mm}$ was found in four participants, as three nodules had diminished and one had grown; the remaining 41 nodules were essentially unchanged. At scintigraphy six nodules were now described as functioning or hot and another six glands were classified as multinodular.

\section{Discussion}

In our unselected population aged 41-71 years from an area with borderline iodine deficiency, $32 \%$ of the participants had one or more thyroid nodules at ultrasonography investigation. Previous studies from areas with different iodine status using ultrasonography as screening in an epidemiological set-up have found nodule prevalences from $4 \%$ (1) to $21 \%$ (12). The tendency is an increased prevalence of nodules in iodine-deficient populations, but this is not a constant phenomenon $(5,14,15,20-22)$. Comparisons of investigations made by different investigators should be done with great care, as classifications are different, the equipment has been improved, and ultrasonography is a subjective procedure. Even trained sonographers from the same centre, using the same equipment, disagree in as many as $55 \%$ of cases with a solitary nodule (23). The lack of correlation of iodine intake with thyroid nodules within this study can also be because of a non-differentiated misclassification, since iodine excretion, as measured by a single casual specimen, does not give a precise indication of iodine status at the individual level.

Nodules were found in $67 \%$ of participants with previous or present hyperthyroidism and only 3.4\% were solitary hot nodules. The main cause of hyperthyroidism in this population thus seems to be multinodular thyroid glands, as would be expected in an area with iodine deficiency, where autonomous areas evolve in non-toxic goitres with time (4). Only half the cases with unrecognized hyperthyroidism had enlarged thyroids and none had clinically obvious goitres, which is 
probably part of the explanation of why so many cases of thyroid dysfunction are overlooked, as hyperthyroidism and goitre are often closely linked together for laymen as well as physicians.

Thyroid size at an ultrasonographic examination is often used as a measure of the iodine status of the population $(2,24)$. A mean thyroid volume of $13.0 \mathrm{ml}$ in the present investigation indicates iodine repletion rather than iodine deficiency compared with a mean thyroid volume of $10.1 \mathrm{ml}$ in Sweden (iodine-replete), $10.9 \mathrm{ml}$ in an area in Italy with borderline iodine deficiency and $21.4 \mathrm{ml}$ in different areas of Germany (generally mild iodine deficiency, iodine excretion median $62.5 \mu \mathrm{g} / \mathrm{g} \mathrm{Cr})(1,25)$. Also in Germany, Hampel et al. (26) found a mean thyroid volume of $22.4 \mathrm{ml}$ in women and $27.8 \mathrm{ml}$ in men. The thyroid size in our population was significantly different from the values found in both the areas investigated by Gutekunst et al. (1) $(P<0.001$, one-sample $t$-test $)$, thus a small difference in iodine excretion may be associated with large differences in thyroid volume. On the other hand, the difference in goitre frequency will be underestimated in our area if only median or mean thyroid volume is considered; the prevalence of thyroid enlargement is probably a more sensitive marker of iodine status. The difference compared with the German results is also supported by the missing age-related increase in thyroid volume in our data, an increase that is expected in iodine-deficient areas, but not in iodine-replete areas $(12,13,27)$.

The slightly increased thyroid volume compared with those in iodine-replete areas and the occurrence of multinodular goitre in particular among the elderly women indicate that at an iodine excretion of $103 \mu \mathrm{g} /$ day, some signs of iodine deficiency are still found. This is in accord with the prevalences of hyperthyroidism and hypothyroidism previously described (18). Being aware of the risk of increasing the prevalence of hypothyroidism to the higher level found in iodinereplete areas, there seems to be evidence for a possible beneficial effect of increasing the iodine intake of this population, and the authorities have just recently initiated an iodine supplement programme (28).

Special attention was paid to the functional status of thyroid nodules, as most malignancies are found in cold rather than in hot or functioning nodules (29), and only solitary nodules were chosen for follow-up, as the risk of malignancy in a multinodular gland is small in an area with endemic multinodularity. Incidental findings of thyroid nodules is an increasing problem with growing use of ultrasonography for examination of not only the thyroid, but also the vessels in the neck, and in general health examinations. By this procedure with primary screening with ultrasonography, solitary, cold thyroid nodules were found in $2.4 \%$ of the general population, with a prevalence independent of age and sex, in contrast to the prevalence of multinodular glands. This prevalence of $2.4 \%$ is in good accordance with Belfiore et al. (10), who found a prevalence of $1.7 \%$ in an iodine-replete area and of $4.3 \%$ in an iodine-deficient area. Our data strongly suggest that thyroid 'incidentalomas' should be regarded differently from clinically apparent nodules with respect to further evaluation, treatment and information to the patients.

The high prevalence of cold nodules is in contrast to the low incidence of diagnosed thyroid cancer. With an incidence of thyroid cancer of approximately 1 per 50000 per year in Denmark (30), only one case of cancer in 20 years is expected in a cohort of this size, further supporting little risk for each nodule; and accordingly, no cancers should be expected in a crosssectional study even of this magnitude. Controversy still exists on the handling of non-palpable nodules in the thyroid as different estimates of the risk of malignancy have been reported $(31,32)$.

In conclusion, we found thyroid volumes slightly increased compared with those in iodine-replete areas, but smaller than in iodine-deficient areas, in this area with borderline iodine deficiency. Thyroid enlargement was found in $6 \%$ of the men and $13 \%$ of the women with an increase with age, related to an increase in the prevalence of nodules in the thyroid. Thyroid enlargement was related to low iodine excretion but not to TPO Ab positivity, whereas thyroid multinodularity was related to TPO Ab positivity but not to low iodine excretion. Solitary, cold thyroid nodules were found in $2.4 \%$ of the participants, unrelated to age and sex, and follow-up 2 years later showed no signs of malignancies, suggesting a conservative attitude to 'incidentalomas'.

\section{Acknowledgements}

This study was supported by grants from the Wedel Wedelsborg foundation, the Agnes and Knut Mørk Foundation, Ortho-Clinical Diagnostics and BRAHMS Diagnostica. Sonographer Rene Fiege should also be acknowledged for the careful and thorough performance of all the ultrasonographies.

\section{References}

1 Gutekunst R, Smolarek H, Hasenpusch U, Stubbe P, Friedrich HJ, Wood WG et al. Goitre epidemiology: thyroid volume, iodine excretion, thyroglobulin and thyrotropin in Germany and Sweden. Acta Endocrinologica 1986112 494-501.

2 Delange F, Benker G, Caron P, Eber O, Ott W, Peter F et al. Thyroid volume and urinary iodine in European schoolchildren: standardization of values for assessment of iodine deficiency. European Journal of Endocrinology 1997136 180-187.

3 Szabolcs I, Podoba J, Feldkamp J, Dohan O, Farkas I, Sajgo M et al. Comparative screening for thyroid disorders in old age in areas of iodine deficiency, long-term iodine prophylaxis and abundant iodine intake. Clinical Endocrinology 199747 87-92.

4 Laurberg P, Pedersen KM, Vestergaard H \& Sigurdsson G. High incidence of multinodular toxic goitre in the elderly population in a low iodine intake area vs high incidence of Graves' disease in 
the young in a high iodine intake area: comparative surveys of thyrotoxicosis epidemiology in East-Jutland Denmark and Iceland. Journal of Internal Medicine 1991229 415-420.

5 Nygaard B, Gideon P, Dige-Petersen H, Jespersen N, Solling K \& Veje A. Thyroid volume and morphology and urinary iodine excretion in a Danish municipality. Acta Endocrinologica 1993 $129505-510$.

6 Aghini-Lombardi F, Antonangeli L, Martino E, Vitti P, Maccherini D, Leoli F et al. The spectrum of thyroid disorders in an iodine-deficient community: the Pescopagano survey. Journal of Clinical Endocrinology and Metabolism 199984 561-566.

7 Slater S. The occurrence of thyroid nodules in the general population. Archives of Internal Medicine 195698 175-180.

8 Vander JB, Gaston EA \& Dawber TR. The significance of nontoxic thyroid nodules. Final report of a 15-year study of the incidence of thyroid malignancy. Annals of Internal Medicine 196869 537-540.

9 Christensen SB, Ericsson UB, Janzon L, Tibblin S \& Trell E. The prevalence of thyroid disorders in a middle-aged female population, with special reference to the solitary thyroid nodule. Acta Chirurgica Scandinavica 1984150 13-19.

10 Belfiore A, La Rosa GL, Padova G, Sava L, Ippolito O \& Vigneri R. The frequency of cold thyroid nodules and thyroid malignancies in patients from an iodine-deficient area. Cancer 198760 3096-3102.

11 Vanderpump MP, Tunbridge WM, French JM, Appleton D, Bates D, Clark F et al. The incidence of thyroid disorders in the community: a twenty-year follow-up of the Whickham Survey. Clinical Endocrinology 199543 55-68.

12 Struve C \& Hinrichs J. Schilddrusenvolumina und Haufigkeit herdformiger Veranderungen bei schilddrusengesunden Mannern und Frauen verschiedener Altersklassen. Deutsche Medizinische Wochenschrift 1989114 283-287.

13 Berghout A, Wiersinga WM, Smits NJ \& Touber JL. Interrelationships between age, thyroid volume, thyroid nodularity, and thyroid function in patients with sporadic nontoxic goiter. American Journal of Medicine 199089 602-608.

14 Carroll BA. Asymptomatic thyroid nodules: incidental sonographic detection. American Journal of Roentgenology $1982138499-501$.

15 Stark DD, Clark OH, Gooding GA \& Moss AA. High-resolution ultrasonography and computed tomography of thyroid lesions in patients with hyperparathyroidism. Surgery 198394 863-868.

16 Laurberg P, Bulow PI, Pedersen KM \& Vestergaard H. Low incidence rate of overt hypothyroidism compared with hyperthyroidism in an area with moderately low iodine intake. Thyroid $1999933-38$

17 Gutekunst R, Becker W, Hehrmann R, Olbricht T \& Pfannenstiel P. Ultraschalldiagnostik der Schilddruse. Deutsche Medizinische Wochenschrift $19881131109-1112$.

18 Knudsen N, Jørgensen T, Rasmussen S, Christiansen E \& Perrild H. The prevalence of thyroid dysfunction in a population with borderline iodine deficiency. Clinical Endocrinology 199951 361-367.
19 Bourdoux P. Biochemical evaluation of iodine status. In Iodine Deficiency in Europe, pp 119-124. Ed. F Delange. New York: Plenum Press, 1993.

20 Tomimori E, Pedrinola F, Cavaliere H, Knobel M \& MedeirosNeto G. Prevalence of incidental thyroid disease in a relatively low iodine intake area. Thyroid 19955 273-276.

21 Woestyn J, Afschrift M, Schelstraete K \& Vermeulen A. Demonstration of nodules in the normal thyroid by echography. British Journal of Radiology 198558 1179-1182.

22 Brander A, Viikinkoski P, Tuuhea J, Voutilainen L \& Kivisaari L. Clinical versus ultrasound examination of the thyroid gland in common clinical practice. Journal of Clinical Ultrasound 199220 $37-42$.

23 Jarlov AE, Nygard B, Hegedus L, Karstrup S \& Hansen JM. Observer variation in ultrasound assessment of the thyroid gland. British Journal of Radiology 199366 625-627.

24 Vitti P, Martino E, Aghini LF, Rago T, Antonangeli L, Maccherini D et al. Thyroid volume measurement by ultrasound in children as a tool for the assessment of mild iodine deficiency. Journal of Clinical Endocrinology and Metabolism 199479 600-603.

25 Tomimori E, Pedrinola F, Cavaliere H, Knobel M \& MedeirosNeto G. Prevalence of incidental thyroid disease in a relatively low iodine intake area. Thyroid 19955 273-276.

26 Hampel R, Kulberg T, Klein K, Jerichow JU, Pichmann EG, Clausen V et al. Strumapravalenz in Deutschland grosser als bisher angenommen. Medizinische Klinik 199590 324-329.

27 Riehl J, Kierdorf H, Schmitt H, Suiter T \& Sieberth HG. Strumapravalenz im Raum Aachen. Sonographische Volumetrie der Schilddruse bei 1336 Erwachsenen in einem Strumaendemiegebiet. Ultraschall in der Medizin 199516 84-89.

28 Rasmussen LB, Andersson G, Haraldsdottir J, Kristiansen E, Molsted K, Laurberg P et al. Iodine. Do we need an enrichment program in Denmark? International Journal of Food Science and Nutrition 199647 377-381.

29 Ashcraft MW \& Van Herle AJ. Management of thyroid nodules. II: Scanning techniques, thyroid suppressive therapy, and fine needle aspiration. Head and Neck Surgery 19813 297-322.

30 Sprogel P \& Storm HH. Thyroid cancer: incidence, mortality and histological pattern in Denmark. International Journal of Epidemiology 198918 990-992.

31 Tan GH \& Gharib H. Thyroid incidentalomas: management approaches to nonpalpable nodules discovered incidentally on thyroid imaging. Annals of Internal Medicine $1997126226-$ 231.

32 Leenhardt L, Hejblum G, Franc B, Fediaevsky LD, Delbot T, Le Guillouzic D et al. Indications and limits of ultrasoundguided cytology in the management of nonpalpable thyroid nodules. Journal of Clinical Endocrinology and Metabolism 1999 $8424-28$.

Received 20 September 1999

Accepted 18 November 1999 